\title{
Implementation of Project-Based Learning (PjBL) in Collaboration Skills and Communication Skills of Students
}

\author{
Yenni Dwi Aprilita Sagala, \\ Graduate student in physics education, \\ Universitas Negeri Medan \\ Medan, Indonesia \\ *Email : ysagala1@gmail.com
}

\author{
Mariati P. Simajuntak, Nurdin Bukit, Motlan \\ Department of Physics , \\ Universitas Negeri Medan, \\ Medan, Indonsia \\ *Email : nurdinbukit5@gmail.com
}

\begin{abstract}
This study aims to (1) determine an increase in collaboration and communication skills through project-based learning, (2) determine the relationship of collaboration skills and communication skills through project-based learning. The population of this research is six classes XI MIA and a sample of this research are two classes, an experiment class with projectbased learning and a control class with conventional. The instrument of collaboration and communication skills are the observation sheet and questionnaire. Improved collaboration and communication skills were analyzed using normalized gain $(\mathbf{N}$ gain). A collaborative relationship with communication using the correlation test. $\mathrm{N}$-gain results show that project-based learning can improve student's collaboration and communication skills, each in the medium category. The relationship between collaboration and communication skills shows a positive direction, which means that the more the collaboration skills increase, the better the student's communication skills.
\end{abstract}

Keywords: Project-Based Learning, collaboration skills, communication skills

\section{INTRODUCTION}

The 21st century people are facing an industrial revolution 4.0 that shows the role of technology that is fast paced and automatic [1]. The existence of the industrial revolution 4.0 challenges humans to have the skills to be able to compete with the progress of the times. Collaboration and communication are skills that must be possessed in order to be able to face the industrial revolution 4.0 [1] [2] [3].

Collaboration is a skill that trains students to work together in order to find solutions to a problem [19]. Roekel defines collaboration as an effort to demonstrate the ability to work effectively and respectfully with diverse teams to achieve shared goals with shared responsibilities [18]. This research focuses on the understanding of collaboration according to Roekel (2011). Collaboration can be trained when producing a work in teaching and learning activities. The exercise will make students work together and effectively so that the expected goals can be realized [4]. These skills need to be trained so that students are able to accept differences and respect each other early and do not prioritize personal interests.
Communication is the art and process of creating and sharing ideas [20]. Roekel also defines communication as an ability to communicate clearly, articulate thoughts and ideas effectively using verbal, written, and nonverbal communication skills in various forms and contexts, listen effectively to decipher meanings, including knowledge, values, attitudes, and effectively in diverse environments including multilingual and multicultural [18].

Learning physics is part of learning science. This study adapted communication from Roekel with Spektor-levy et al to fit the learning of science [5] [18]. In fact in the field the results of students' scientific communication skills are still low. Students have a level of reading results that are still low, have not been able to retrieve information from reliable reference sources, and have not been able to display illustrations through graphics or pictures.

One learning model that can practice collaboration and communication skills is the project based learning (PjBL) model [6]. This is because the stages of learning that will occur require students to collaborate to solve problems and achieve desired goals. During the process of finding these solutions, students will also communicate, both when searching for sources, deciding on the right solution, to presenting the results of discussions that have occurred. This is also supported by the results of previous studies [7] [8] [9] [10].

\section{THEORY}

\section{A. Project Based Learning (PjBL) Model}

The PjBL model is a learning model that starts from project planning and development by producing a work in the form of products that can be presented and published [11]. The steps of the PjBL model in this study are based on [11] which consists of five steps, namely: (1) Finding ideas, (2) Designing projects, (3) Arranging project arrangements, (4) Implementing projects, and (5) Assess the product produced.

This model also has advantages, namely (1) increasing motivation [8], (2) increasing learning outcomes [12], (3) 
increasing collaborative abilities [7], (4) improving communication skills [7], (5) increasing skills to manage learning resources [13], (6) make learning fun [14], (7) improve student ethics [13], (8) increase student creativity [15], (9) reduce the level of anxiety / fear during learning activities teaching [16], (10) improving problem solving skills [17], (11) improving resource management skills [17].

\section{B. Collaboration Skills}

Collaboration skills are an effort to demonstrate the ability to work effectively and respectfully with diverse teams to achieve shared goals with shared responsibilities.

Students who are skilled at collaborating will be able to accept differences by respecting one another and prioritizing shared interests to achieve common goals. The success of collaboration skills can be known by fulfilling the indicators created in the rubric used, while the collaboration assessment indicators are adapted from Buck Institute for Education [18]. The reason for selecting this indicator is because it provides a concise and clear breakdown and the availability of an assessment rubric.

Indicators of collaboration are: (1) taking responsibility for oneself, (2) helping groups, (3) respecting others, (4) making and following agreements, (5) organizing work, and (6) working as a whole group.

\section{Communication Skills}

Communication skills are as an ability to communicate clearly, articulate thoughts and ideas effectively using verbal, written, and nonverbal communication skills in various forms and contexts, listen effectively to describe meaning, including knowledge, values, attitudes, and effectively in the environment diverse including multilingual and multicultural [18]. Physics is a science learning, so the communication referred to in this study is scientific communication. Good scientific communication must be able to measure communication skills in learning science. Indicators of scientific communication skills according to [5], as in Table 1.

TABLE I. COMMUNICATION INDICATORS AND SUB-INDICATORS

\begin{tabular}{|l|l|}
\hline \multicolumn{1}{|c|}{$\begin{array}{c}\text { Indicators of } \\
\text { Communication }\end{array}$} & \multicolumn{1}{|c|}{ Sub Indicator (Example) } \\
\hline Search information & $\begin{array}{l}\text { Taking information in a computer } \\
\text { database, instructions in the library, } \\
\text { using catalogs, interviewing experts }\end{array}$ \\
\hline Read scientifically & $\begin{array}{l}\text { Read scientific articles, get to know } \\
\text { the reference books used, read } \\
\text { research reports or news. }\end{array}$ \\
\hline Listening and observing & $\begin{array}{l}\text { Resources that can be used are } \\
\text { teachers, debates, } \\
\text { demonstrations. }\end{array}$ \\
\hline Write scientifically & $\begin{array}{l}\text { Posts can be contained in the form of } \\
\text { articles, reports, abstracts, scientific } \\
\text { essays. }\end{array}$ \\
\hline Presenting information & $\begin{array}{l}\text { Information can be presented again in } \\
\text { the form of schemes, graphs, tables, }\end{array}$ \\
\hline
\end{tabular}

\begin{tabular}{|l|l|}
\hline $\begin{array}{c}\text { Indicators of } \\
\text { Communication }\end{array}$ & \multicolumn{1}{|c|}{ Sub Indicator (Example) } \\
\hline & $\begin{array}{l}\text { pictures or illustrations, using } \\
\text { multimedia, panelists, and scientific } \\
\text { posters. }\end{array}$ \\
\hline
\end{tabular}

\section{METHOD}

This study uses one class subject with no control class. The subjects of this study were treated and observed to see improvement in collaboration and communication skills.

The population in this study were all students of class XI Science (MIA) Senior High School State 12 Medan (SMA Negeri 12 Medan) E.Y. 2019/2020, this research took place in the first semester of E.Y. 2019/2020. This research sample is a class XI Science (MIA). The research instrument used was the observation sheet and questionnaire. Data is collected based on observers' results using the rubric provided (observation sheet) and filled out by students (questionnaire sheet). Analysis of the data used respectively is the normalized gain (N-gain) to see improvements in collaboration and communication skills and correlations to see the effect of the collaboration relationship on communication.

\section{RESULT AND DISCUSSION}

Data collection conducted in this study was to use an observation sheet that was observed by observers and questionnaires filled out by students.

\subsection{Collaboration Results}

\subsubsection{Observation sheet}

The average and overall improvement in the results of the student collaboration observation sheet and each indicator can be seen in Table 2 .

TABLE II. AVERAGE AND IMPROVEMENT OF COLlaboRATION OBSERVATION SHEET RESULTS

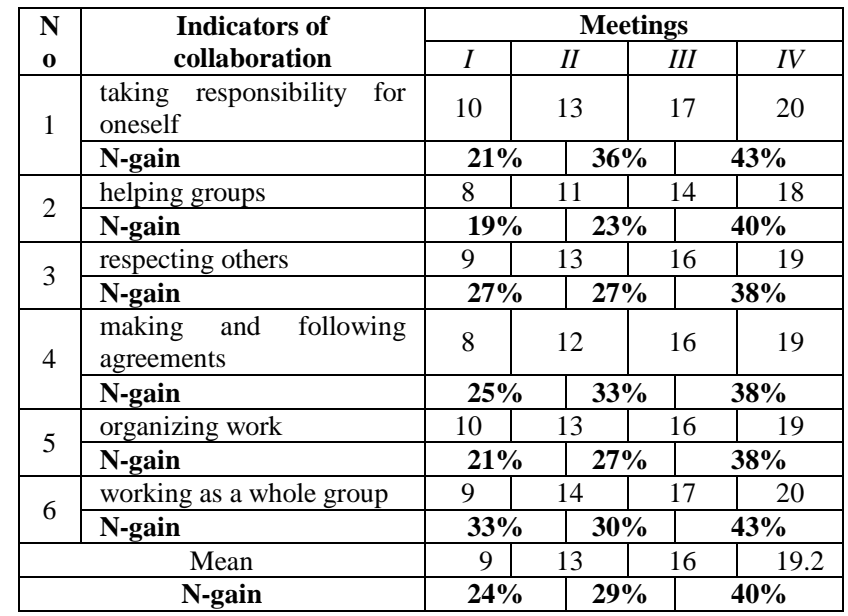

The data above is obtained by using the $\mathrm{N}$-gain equation by comparing the average of the meeting after the previous and 
then divided by the difference between the maximum number of observations with the results of the previous meeting. The maximum number of scores on this observation sheet is 24 . Mathematically to obtain an $\mathrm{N}$-gain of $21 \%$ on the first indicator is: $N-\operatorname{gain}=\frac{13-10}{24-10} * 100 \%=21 \%$

Likewise for further results. Based on the data, the average collaboration skills in Table 2 show an increase in the collaboration skills of students who are taught using the $\mathrm{PjBL}$ model, where the results indicate a medium category.

\subsubsection{Questionnaire}

The average collaboration and improvement questionnaire overall and each indicator are categorized in Table 3.

TABLE III. AVERAGE AND IMPROVEMENT OF COLLABORATION QESTIONNAIRE SHEET RESULTS

\begin{tabular}{|c|c|c|c|c|c|}
\hline \multirow{2}{*}{ No } & \multirow{2}{*}{ Indicators of collaboration } & \multicolumn{4}{|c|}{ Pertemuan } \\
\hline & & $I$ & $I I$ & $I I I$ & $I V$ \\
\hline \multirow[t]{2}{*}{1} & $\begin{array}{lll}\text { taking } & \text { responsibility } & \text { for } \\
\text { oneself } & & \end{array}$ & 53 & 75 & 95 & 115 \\
\hline & $\mathrm{N}$-gain & $25 \%$ & \multicolumn{2}{|c|}{$31 \%$} & $44 \%$ \\
\hline \multirow{2}{*}{2} & helping groups & 39 & 60 & 79 & 102 \\
\hline & $\mathrm{N}$-gain & $21 \%$ & \multicolumn{2}{|c|}{$24 \%$} & $38 \%$ \\
\hline \multirow{2}{*}{3} & respecting others & 45 & 69 & 90 & 110 \\
\hline & N-gain & $25 \%$ & \multicolumn{2}{|c|}{$30 \%$} & $40 \%$ \\
\hline \multirow[t]{2}{*}{4} & $\begin{array}{l}\text { making and following } \\
\text { agreements }\end{array}$ & 44 & 69 & 88 & 105 \\
\hline & $\mathrm{N}$-gain & $26 \%$ & \multicolumn{2}{|c|}{$27 \%$} & $33 \%$ \\
\hline \multirow{2}{*}{5} & organizing work & 54 & 79 & 99 & 115 \\
\hline & N-gain & $29 \%$ & \multicolumn{2}{|c|}{$33 \%$} & $39 \%$ \\
\hline \multirow{2}{*}{6} & working as a whole group & 40 & 60 & 87 & 111 \\
\hline & N-gain & $20 \%$ & \multicolumn{2}{|c|}{$34 \%$} & $45 \%$ \\
\hline \multicolumn{2}{|r|}{ Mean } & 46 & 69 & 90 & 110 \\
\hline & $\mathrm{N}$-gain & $24 \%$ & \multicolumn{2}{|c|}{$29 \%$} & $40 \%$ \\
\hline
\end{tabular}

Based on the average value of the questionnaire on each indicator of collaboration skills in Table 3 which shows that the results of the observation sheet are in line with the results of the questionnaire filled out by students.

\subsection{Communication Skills Results}

\subsubsection{Observation sheet}

Average and overall improvement in the results of student communication observation sheets and each indicator can be seen in Table 4.

TABLE IV. AVEREgE AND IMPROVEMENT OF COMMUNICATION OBSERVATION SHEET RESULTS

\begin{tabular}{|c|c|c|c|c|c|}
\hline \multirow{2}{*}{ No } & \multirow{2}{*}{ Communication indicator } & \multicolumn{4}{|c|}{ Meetings } \\
\hline & & $I$ & $I I$ & $I I I$ & $I V$ \\
\hline \multirow{2}{*}{1} & Search information & 5 & 8 & 11 & 15 \\
\hline & $\mathrm{N}$-gain & \multicolumn{2}{|l|}{$20 \%$} & \multicolumn{2}{|c|}{$44 \%$} \\
\hline \multirow{2}{*}{2} & Read scientifically & 6 & 9 & 12 & 15 \\
\hline & $\mathrm{N}$-gain & \multicolumn{2}{|l|}{$21 \%$} & \multicolumn{2}{|c|}{$38 \%$} \\
\hline \multirow{2}{*}{3} & Listening and observing & 5 & 9 & 13 & 16 \\
\hline & N-gain & \multicolumn{2}{|l|}{$27 \%$} & \multicolumn{2}{|c|}{$43 \%$} \\
\hline \multirow{2}{*}{4} & Write scientifically & 7 & 10 & 13 & 15 \\
\hline & N-gain & \multicolumn{2}{|l|}{$23 \%$} & \multicolumn{2}{|c|}{$29 \%$} \\
\hline 5 & Presenting information & 8 & 12 & 15 & 17 \\
\hline
\end{tabular}

\begin{tabular}{|c|c|c|c|c|c|}
\hline \multirow{3}{*}{ No } & \multirow{2}{*}{ Communication indicator } & \multicolumn{4}{|c|}{ Meetings } \\
\hline & & $I$ & II & III & $I V$ \\
\hline & $\mathrm{N}$-gain & \multicolumn{2}{|c|}{$33 \%$} & $38 \%$ & $40 \%$ \\
\hline \multicolumn{2}{|r|}{ Mean } & 6 & 10 & 13 & 16 \\
\hline & $\mathrm{N}$-gain & \multicolumn{2}{|c|}{$25 \%$} & & $39 \%$ \\
\hline
\end{tabular}

Same with collaboration skills, this data is obtained by using the $\mathrm{N}$-gain equation by comparing the average of the meeting after the previous and then divided by the difference between the maximum number of observations with the results of the previous meeting. The maximum number of scores on this observation sheet is 20. Mathematically to obtain an Ngain of $20 \%$ on the first indicator is:

$$
N-\text { gain }=\frac{8-5}{20-5} * 100 \%=20 \%
$$

The average communication skills in Table 4 show an increase in students' communication skills taught using the $\mathrm{PjBL}$ model, where the results indicate a medium category.

\subsubsection{Questionnaire}

The overall communication and improvement questionnaire overall and each indicator are categorized in Table 5.

TABLE V. AVERAGE AND IMPROVEMENT IN COMMUNICATION QUESTIONNAIRE RESULTS

\begin{tabular}{|c|c|c|c|c|c|}
\hline \multirow{2}{*}{$\begin{array}{l}\mathbf{N} \\
\mathbf{0}\end{array}$} & \multirow{2}{*}{$\begin{array}{c}\text { Communication } \\
\text { indicator }\end{array}$} & \multicolumn{4}{|c|}{ Meetings } \\
\hline & & I & II & III & IV \\
\hline \multirow{2}{*}{1} & Search information & 45 & 63 & 77 & 88 \\
\hline & N-gain & \multicolumn{2}{|c|}{$31 \%$} & $34 \%$ & $41 \%$ \\
\hline \multirow{2}{*}{2} & Read scientifically & 49 & 67 & 80 & 89 \\
\hline & N-gain & \multicolumn{2}{|c|}{$33 \%$} & $35 \%$ & $38 \%$ \\
\hline \multirow{2}{*}{3} & Listening and observing & 51 & 69 & 82 & 92 \\
\hline & N-gain & \multicolumn{2}{|c|}{$34 \%$} & \multicolumn{2}{|c|}{$45 \%$} \\
\hline \multirow{2}{*}{4} & Write scientifically & 35 & 56 & 71 & 82 \\
\hline & N-gain & \multicolumn{2}{|c|}{$30 \%$} & $31 \%$ & $33 \%$ \\
\hline \multirow{2}{*}{5} & Presenting information & 50 & 65 & 78 & 88 \\
\hline & N-gain & \multicolumn{2}{|c|}{$28 \%$} & \multicolumn{2}{|c|}{$38 \%$} \\
\hline \multicolumn{2}{|r|}{ Mean } & 46 & 64 & 78 & 88 \\
\hline & $\mathrm{N}$-gain & \multicolumn{2}{|c|}{$31 \%$} & \multicolumn{2}{|c|}{$39 \%$} \\
\hline
\end{tabular}

Based on the average value of the questionnaire on each indicator of communication skills in Table 5 which shows that the results of the observation sheet are in line with the results of the questionnaire filled out by students.

\subsection{Discussion}

The PjBL model in this study uses the syntax of Patton (2012), which consists of five phases, namely (1) Finding ideas, (2) Designing projects, (3) Arranging project settings, (4) Implementing projects, and (5) Assessing products that generated. Learning on the topic of temperature and heat starts with the phase of finding ideas. Finding ideas means students are given a contextual problem, related to the topic of temperature and heat to be solved together. Students will be challenged to think. Scientific communication activities that occur in this phase are students communicating to retrieve information related to the topic given, both from books, the internet, and reference sources provided by the teacher. In line with communication activities, students also collaborate by 
working together to get the information needed from each student so that the group has a strong basis for solving problems. The first meeting, students are not used to it and there are still many who are confused, but at the next meeting students begin to get used to reading each source, then compare and agree on ideas to be made.

The project design phase requires students to arrange work timelines, manage projects to be created, and the division of tasks of each group member where this is in line with collaborative activities. Students will collaborate to reach mutual agreement in determining the organization and division of tasks of the group. The teacher also communicates the indicators to be assessed, so students are more directed and focused on completing the task. The scientific communication activities that occur in this phase are listening and observing sources provided by the teacher, videos, and demonstrations.

The phase of constructing a project means that the student will prepare a model of the project being worked on. Respect for others will be seen in this phase, where advice is needed from group members to provide an overview of the project model to be agreed upon. Initially there was each group, there were 1-2 people who did not want to be involved, even though they knew something was wrong. Encouragement from the teacher is needed at this stage in order to maximize the workings of each group member. The teacher also emphasizes the results of this group are not for themselves, but rather a shared responsibility. Typical writing activities also occur in this phase.

The project implementation phase allows students to implement project models that have been mutually agreed upon. The teacher can observe the activities of mutual respect, complete cooperation, helping each other in groups. The project is designed to be completed at each meeting, so good collaboration and communication is needed at this phase. Several times students have difficulty at this stage, but with good cooperation the project can be completed. The first meeting there is one group that is not ready to complete the project, but the next meeting of each project can be completed properly.

The final phase in this $\mathrm{PjBL}$ model is assessing the product. The product is assessed through group presentations in front of the class. A good group in communicating is proven by providing clear discussion results, in accordance with the actual situation and can present illustrations through graphs, tables, or pictures. Collaborative activities such as respecting others can also occur at this stage. This is because during the discussion (questions, criticisms / suggestions) from other groups to the group presenting. Full cooperation is also demanded to occur in the group presenting.

The results of the collaboration and communication assessment on each indicator can be seen in tables 1 and 2 .

Based on the table produced communication results of each indicator showed an increase in the medium category. The results of the collaboration of each indicator also show in the medium category. Based on the results obtained, it can be seen that student collaboration skills are comparable to student communication. This is also supported by the results of previous researchers [6] [7] [8] [9] [10] [21].

\section{CONCLUSION}

Based on the results and discussion of research shows that project-based learning can improve student collaboration and communication skills, each in the medium category. The relationship between collaboration and communication skills shows a positive direction, which means that the more the collaboration skills increase, the better the students' communication skills.

\section{ACKNOWLEDGMENT}

A sincere thanks to the Ministry of Research, Technology and Higher Education through post-graduate research grants that have provided funds to support the implementation of this research based on SK No. 190/SP2H/LT/DRPM/2019.

\section{REFERENCES}

[1] A. Savitri. Revolusi Industri 4.0. Yogyakarta: Genesis, 2019. (references)

[2] A. Saavedra and V. Opfer, "Learning $21^{\text {st }}$-century skills requires $21^{\text {st }}$ century teaching," in The Phi Delta Kappan, $2^{\text {nd }}$ ed, vol. 94, pp. 8-13, 2012. in press.

[3] C. Kivunjav, "Exploring the Pedagogical Meaning and Implications of the 4Cs "Super Skills" for the 21st Century through Bruner's 5E Lenses of Knowledge Construction to Improve Pedagogies of the New Learning Paradigm," in Creative Education, Scientific Research Publishing, vol. 6, pp. 224-239, 2015. in press.

[4] L. Greenstein, "Assessing $21^{\text {st }}$ Century Skills: A Guide to Evaluating Mastery and Authentic Learning," California: Corwin, 2012. in press.

[5] O. Spektor-levy, B. Eylon, and Z. Scherz, "Teaching communication skills in science: Tracing teacher change," in Teaching and Teacher Education, vol. 24, pp. 462-477, 2008. in press.

[6] J. L. Shih, C. W. Chuang, and G. J. Hwang, "An inquiry-based mobile learning approach to enhancing social science learning effectiveness," in Educational Technology \& Society, $4^{\text {th }}$ ed, vol. 13, pp. 50-62, 2010. in press.

[7] S. A. Yalçin, U. Turgut, and E. B y kkasap, "The effect of PBL on science undergraduates' learning of electricity, attitude towards physics and scientific process skills," in International Online Journal Of Educational Sciences, $1^{\text {st }}$ ed, vol. 1, pp. 81-105, 2009. in press.

[8] J. R. Elam and B. Nesbit, "The effectiveness pf PBL utilizing Web 2.0 Tools in EFL," in The JALT Call Journal, 2nd ed, vol. 8, pp. 113-127, 2012. in press.

[9] S. A. Brusic, and K. L. Shearer, "The ABCs of $21^{\text {st }}$ century skill (cover story)," in Childrens's Technology \& Engineering, $4^{\text {th }}$ ed, vol. 18, pp. 610, 2014. in press.

[10] S. Saenab, S. R. Yunus, A. R. Saleh, A. N. Virninda, L. Hamka, and N. A. Sofyan, "Project-based Learning as the Atmoshphere for Promoting Students' Communication Skills," in Journal of Physics: Conference Series, $1^{\text {st }}$ ed, vol. 1028, 2018. in press.

[11] A. Patton, Work that Matters The Teacher's Guide to Project Based Learning. Paul Hamlin Foundation: UK, 2012. in press.

[12] N. R. Ergul, and E. K, "Kargin, The effect of PBL on students" science success," in Procedia - Social And Behavioral Sciences, vol. 136, pp. 537-541, 2014. in press. 
[13] I. Morgil, H. G. Seyhan, E. U. Alsan, and S. Temel. "The effect of web based project applications on students' attitudes towards chemistry," in Turkish Online Journal Of Distance Education-Tojde, $2^{\text {nd }}$ ed, vol. 9, 2008. in press

[14] N. F. Jumaat, D. Tasir, "Integrating project based learning environment into the design and development of mobile apps for learning 2Danimation," in Paper presented at $13^{\text {th }}$ International Educational Technology Conferences, pp. 567-572. in press.

[15] C. F. Zhou, J. E. Holgraard, A. Kolmos, and J. D. Nielsen, "Creativity development for engineering students: Cases of problem and project based learning," in Paper presented at Joint International IGIP-SEFI Annual Conferences 2010, Tranava, Slovakia. in press.

[16] D. Erdem, "Examination of the effects of PBL approach on students' attitudes towards chemistry and test anxiety," in World Applied Sciences Journal, $6^{\text {th }}$ ed, vol. 17 , pp. $764-769,2012$. in press.
[17] W. Sumarni, "The Strength and Weakness of the Implementation of Project Based Learning: A Review," in International Journal of Science and Research, $3^{\text {rd }}$ ed, vol. 4, pp. 478-484, 2013. in press.

[18] D. V. Roekel, "Preparing 21st Century students For a Global Society an Educator's Guide to the"Four Cs," in National Education Association: Canada, 2011. in press.

[19] T. Goradia, "Role of Educational Technologies Utilizing the TPACK Framework and 21st Century Pedagogies: Academics' Perspectives," in IAFOR Journal of Education, $3^{\text {rd }}$ ed, vol. 6, pp. 43-61, 2018. in press.

[20] M. Training, "Effective Communication Skills," in Mtd Training \& Ventus Publishing Aps, 2010. in press.

[21] W. Fadly, and Wasis, "Fostering Student's Communication through PjBL-based Communication Activities," in Journal of Research \&Method in Education, $3^{\text {rd }}$ ed, vol. 7, pp. 21-26, 2017. in press. 